\title{
فاعلية التدريب الفتري مرتفع الثدة علي بعض المتغيرات البدنية للاعبي الريثة الطائرة
}

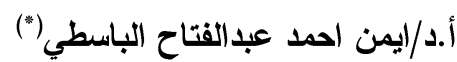

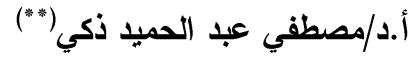

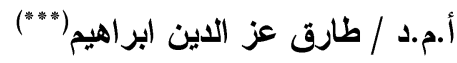

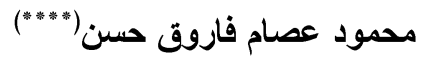

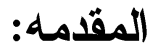

إن المستوى الرياضي المتقدم الذي وصلت إلية دول كثيرة هو نتيجة للتقدم الذي شهده العـالم

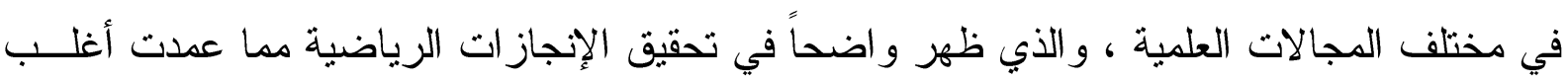
الدول إلى إستخدام أفضل الأساليب والأدوات التدريبية في المجال الرياضي من أجل الوصول باللاعب إلى مستوى عالي في أداء المهارات الأساسية لأي لعبة ، ولذا كان هدف أي مدرب هو توجيه الجهود لتحقيق الانجاز ، فكان إلزاما علية استخدام التخصصية في التّريب و التركيز علــى متطلبـات الأداء الفني في نوع الفعالية الرياضية ، إذ تعد خصوصية التدريب أحد القوانين الأساسية التي تحكم عمليــة التدريب في تحقيق الهدف منها و هو المستوى العالي من الإنجاز .( : IV ( )

ويؤكد " بسطويسى أحمد (999 (9) بأن التدريب الفتري مرتفع الثدة هو تدريب قصير المدى

ويتميز بارتفاع في شدة وحجم التدريب للوصول إلى الفورمة الرياضية وذلك بتغير ديناميكية حمل التدريب (الثدة - الحجم) دون ضمان استمرار على مدار الموسم التدريبي التتافسي. (10: ( MT), rA.

التدريب الفتري مرتفع الثدة هو تدريب قصير المدى ويتميز بارتفاع في الثندة والحجم للوصول إلى" الفورمة الرياضية " وذلك بتغير ديناميكية حمل التدريب " الثدة - الحجم " دون ضمان استمر اره على مدار الموسم التدريبي التنافسي. أي الزيادة السريعة في شدة المثبر للتدريب مع ثبات الحجم أو زيادة قليلة في الحجم. التدريب الفتري مرتفع الثدة عبارة عن زيادة الأحمال التدريبية ورفع شدة التدريب بدرجة عالية لمدة قصيرة مما يؤدى إلى تحقيق الفورمة الرياضية في أسرع وقت مدكن

$($ KT:OS)

(") استاذ بقسم نظريات وتطبيقات رياضات المضرب بكليه التزبيه الرياضيه للبنين - جامعه الزقازيق.

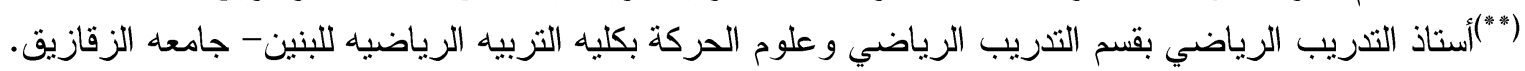

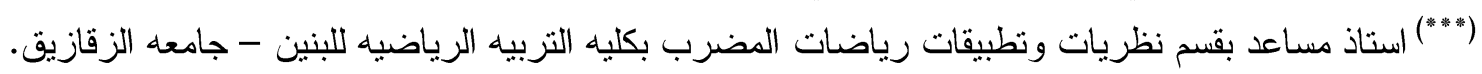

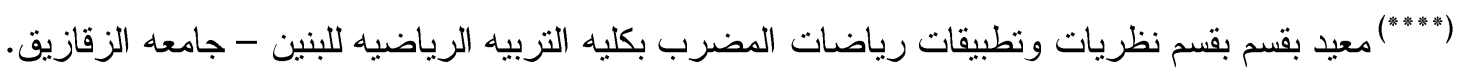


يشير " على البيك وعماد عباس " (r . . r) أن التدريب الفتري مرتفع الثدة يستخدم للأسباب الاتية بعد أن يكون اللاعب قد انقطع عن التدريب لفترة من الزمن أو بالتدريب بالقدر غير الكافي

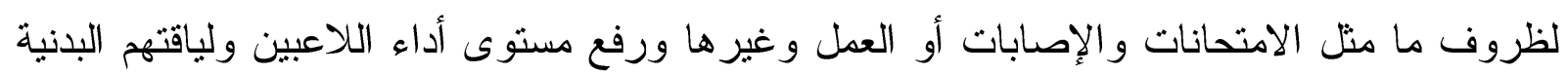

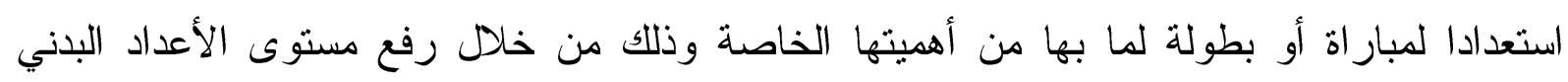

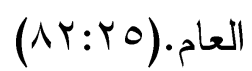

ومن خلا الاطلاع على الدراسات السابقة ( 9 ، . 1 ، 17 ) تبين للباحث أن التدريب الفتري مرتفع الثدة هو زيادة الأحمال التنريبية عن طريق رفع درجة الحمل التدريبي لدرجة عالية لفترة قصيرة، يستطيع معها اللاعب الوصول للفورمة الرياضية في أسر ع وقت مدكن. وتعد رياضة الريشة الطائرة واحدة من أسرع الرياضات العالمبة التي تتسم بالسرعة و أكثرها

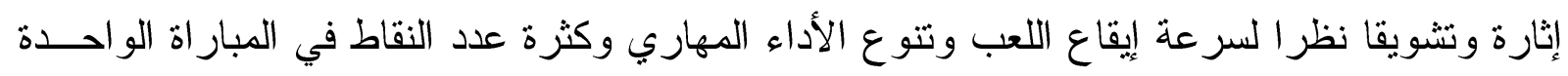
حيث يظل اللاعبون يتتافسون طوال المبار اة من أجل الفوز بأكبر عدد من النقاط ـ (10 إع أ) ويذكر مبارك رضــا (ع . . rم) إن لعبة الريشة الطائرة واحدة من أشهر الألعاب الرياضية في العالم فهي لعبة تتاسب كل الأعمار ومستويات المهارة المتتوعة وكذلك يمكن للرجال و النساء من جميع

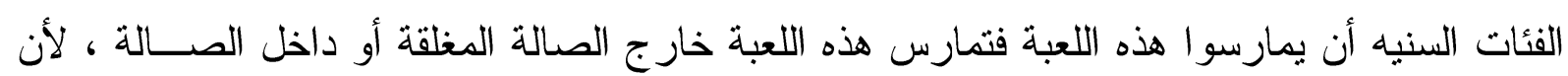
الريشة ( ريثة مثبته في قاعدة من الفلين تقفف بمضرب ) تقفز ويجب لعبها في الهو اء ـ لـــذلك فــإن

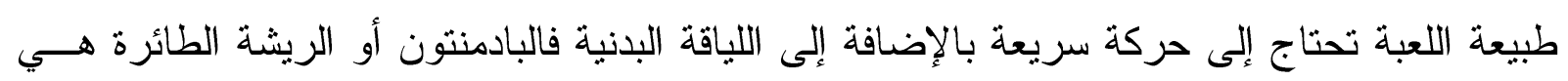

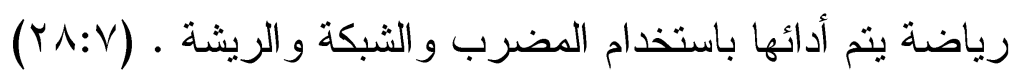

إن المتغيرات البدنية هي الطريق للوصول إلي القمة لذا يجب علي المدرب إعداد لاعبية ليصلو

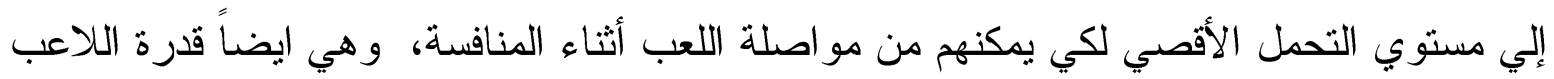
علي التفاعل السريع مع كافة المؤثرات التى تواجهه وبشكل يضمن المحافظة علي التوازن المطلوب، و هي درجة إستعداد اللاعب البدني و النفسي بشكل يؤهله علي تحقيق إنجاز العمل الرياضي بصورة

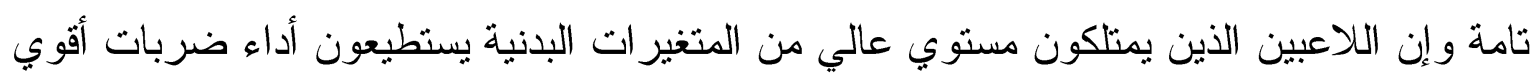
و التحرك داخل الملعب بصورة سهلة مما يساعدهم للوصول إلي الريشة بسرعة ورشاقة . (N (1) 
كما أن أول ما يلفت انتباه من يشاهد مباريات الريشة الطائرة تلك التحركات السريعة من الأمام إلى الخلف أو بالعكس أو من جانب إلى آخر لأداء المهارات الحركية المختلفة الأمر الذي هني يتطلب قدرات بدنية عالية ولأن الحركة العادية للريشة في الهواء بطيئة للطبيعة التركيبية ريشة ، فإن الضربات تتطلب قوة مناسبة لإرسال الريشة لحدود الملعب خلفي ، كما أن من أهم منطلبات الريشة الطائرة أثناء المبار اة هي الاستجابة السريعة وردود الفعل الخاطفة نظر الخفة الريشة و السرعة التي تضرب بها بالإضافة إلى قدرة اللاعب في التحرك السريع وتغيير الاتجاه للوصول للريشة ، و الدفاع عن مساحة كبيرة نسبيا الأمر الذي يستوجب القيام بعمل تحركات سريعة بالرجلين غالبا ما تتنهي بعمل طعن لتعويض المسافة و الوصول للريشة في التوقيت المناسب قبل سقوطها على الأرض ، و هذا يتطلب المطاطية المناسبة للعضلات ، وأن يمنالك اللاعب التوافق الجيد بين تحركات القدمين وحركات الذراع الحاملة للمضرب ومتابعة الريشة المضروبة من المنافس والدقة في توجيه الريشة للمكان المناسب في ملعب المنافس.(Y (Y I ( )

\section{ثانيا: مشكلة البحث}

تتمتل فكرة البحث في إنخفاض الجانب البدني للاعبين المستويات العلبا و التي تؤثر علي الحالة التدريبية و الفورمة الرياضية علي مدار الموسم التدريبي بالرغم من اهتلالك اللاعبيين مستوي مهاري وخططي عالي ولكن ينقصهم الجانب البدني ويظهر ذلك أثناء المباريات حيث أن اللاعبين يبدؤون المباراة بشكل جيد ثم مع مرور الوقت يبدأ المستوي في الانخفاض السريع ، وكذلك بسبب عدم تحقيق نتائج جيدة للعينة قيد البحث علي المستوي المحلي وتميز بعض الفرق الأخرى عن العينة قيد البحث وذلك بسبب عدم وجود مخطط أحمال لايهم يخطط للأحمال البدنية بشكل علمي مقنن ، و عندما أسند إلي الباحث تخطيط الأحمال التدريبية للفريق وبدأ بعمل الاختبارات البدنية والحركية التي تم تتفيذها علي اللاعبين وجد ان هناك قصور كبير في بعض المتغيرات البدنية لدي اللاعبين وذلك بسبب عدم الأهنمام بالجانب البدني و الحركي لدي اللاعبين .

كما أن طريقة التدريب الفتري مرتفع الثدة تتلاعم مع طبيعة المسابقات التتافسية في الريشة الطائرة حيث أنها تتميز بزيادة سريعة في شدة التثريب مع ثبات الحجم و التقليل التنريجي في فترات الراحة، وبالتالي قد يكون له تأثثر سريع في الوصول إلى الفورمة الرياضية، على ان يلي ذلك خفض متدرج ومقصود للأحمال التدريبية قبل رفعها مرة اخرى، حتى يمكن الوصول للفورمة الرياضية 
بصورة سريعة مع المحافظة على هذه الفورمة وعدم تعرض اللاعب لظاهرة التدريب الزائد، مما يؤهل اللاعب للأداء المتميز خلال المنافسات الرياضية.

ومن خلال عمل الباحث كمخطط احمال لفريق طلائع الجيش لاحظ أن الموسم الرياضي قصير جدا يتراوح بين r : م أثهر وتمتل هذه الفتره كل مراحل البرنامج من فترة اعداد وفترة منافسات وفترة انتقالية وهي فترة غير كافية لإعداد اللاعبين للوصول بهم إلى أفضل مستوى ممكن

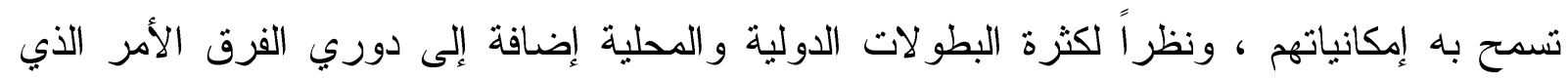
يتطلب استخدام تدريب فتري مرتفع الثدة يتلاءم مع ظروف قصر الفترة التدريبية ، مما يساهم في

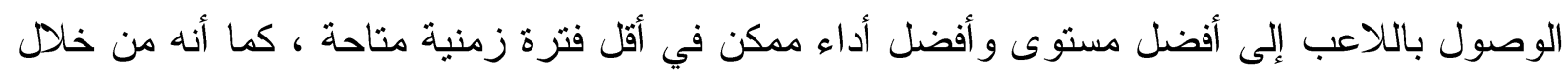
إطلاع الباحث - في حدود علمه على المراجع العلمية في مجال التدريب الرياضي عامة وتدريب رياضة الريشة الطائرة خاصة وجد أن أنسب طريقة لتحقيق الهدف السابق هي التنريب الفتري مرتفع الثدة

ويعتبر هذا البحث محاولة جادة لمساعدة المدربين على معرفة أي الأساليب أفضل لتطوير المستوي البني في فتزة الإعداد العام والخاص للوصول باللاعب إلى المستويات الرياضية العليا دون إصابات أو الوصول إلى الإجهاد بسبب التدريب الزائد، وهذا الأمر يتطلب العديد من الدراسات العلمية لتحديد تأثير التدريب الفتري مرتفع الثدة سواء على الناحية البدنية الني تعتبر الأساس لجميع المهارات

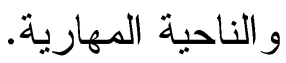

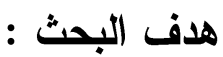

التعرف على فاعلية التدريب الفتري المرتفع الثدة علي بعض المتغيرات البدنية للاعبي الريشة

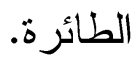

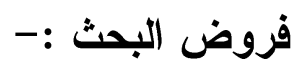

توجد فروق دالة إحصائيه بين كل من القياس القبلى و البعدى لعينة البحث علي بعض المتغيرات البدنية للاعبي الريشة الطائرة..

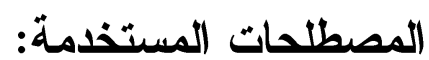




$$
\text { التدريب الفتري مرتفع الثدة : }
$$

هو احد طرق التدريب التي تتميز بزيادة في شدة الاحمال التدريبية مع وجود فترات راحة إيجابية غير كاملة أي أنها تتمثل في سلسلة دن تكرار فترات التمرين بين كل تكرار والاخر فترة راحة ايجابية غير كاملة بحيث لا تعود فيها ضربات القلب لدي اللاعب إلي حالتها الطبيعية .( ( 1 (1))

\section{الار اسات السابقة: - ت}

قام الباحث بإجر اء مسح مرجعي للبحوث العلمية والمجلات و الدوريات العلمية سواء العربيـة منها أو الأجنبية من خلال شبكة المعلومات الدولية و المكتبات بكليات التربية الرياضــية فـي حـدود إمكانات الباحث ، حيث يتضمن هذا الجزء عرضاً للار اسات التي تتاولت التدريب الفتري مرتفع الثدة ، وقد تتاولت هذه الدراسات بعض الجوانب التي تهح الباحث وتساعده في إجر اء بحثه الحالي حتى تكون مرشدا له في اختيار الأهداف وكيفية السير في إجر اءاته والوقوف علي ما توصلت إليه هذه الدراسات من نتائج تفيد الباحث في معالجة بيانات بحثه إحصائياً للتوصل للنتائج ومن ثم مناقشتها .

\section{أولا: الدراسات السابقة العربيه:.}

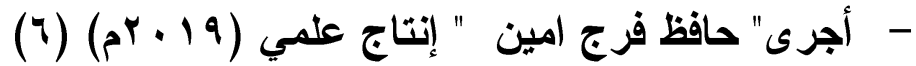

در اسة تأثثر استخدام التدريب الفترى المرتفع الثدة على تطوير القوة المميزة بالسرعة لعدو مسافة . .. متر وذللك بهدف التعرف على مدى تأثير بعض تمارين التدريب الفتري على تحسين مستوى الإنجاز في فعالية عدو .ع، واستخدم الباحث المنهج التجريبى واشتملت عينة البحث على ( ع ) لاعب وكانت اهم النتائج أن هناك تأثير لتمارين التدريب الفتري على تحسين مستوى الإنجاز في فعالية عدو . . عم.

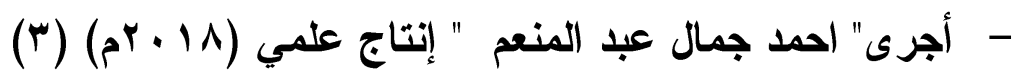

در اسة تأثثر التدريب الفتري مرتفع الثدة على القـدرات البدنيــة الخاصـــة وبعـض المؤشرات البيولوجية و المستوى الرقمي لمنسابقي . . 10 متر جري وذللك بهدف تأثير التذريب الفترى مرتفع الثدة على القدر ات البدنية الخاصة وبعض المؤشرات البيولوجية و المستوي الرقمي لمتســابقي 


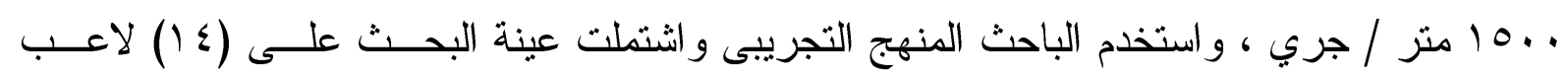
وكانت اهم النتائج فروق ذات دلالة إحصائية بين القياسين البعديين للمجموعة التجريبيــة و الضــابطة ولصالح القياس البعدي للمجموعة التجريبية في بعض القدرات البدنية الخاصة وبعـض المؤشــرات

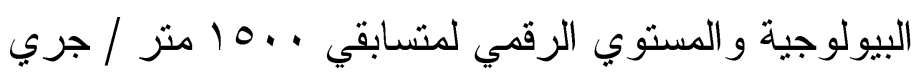

\section{- أجرى" نالان صلاح صالح " إنتاج علمي (V ا + rم) ( l )}

دراسة عنو انها تأثير التدريب الفتري المنخفض و المرتفع الثدة في تطـــوير القــدرات البدنيـــة

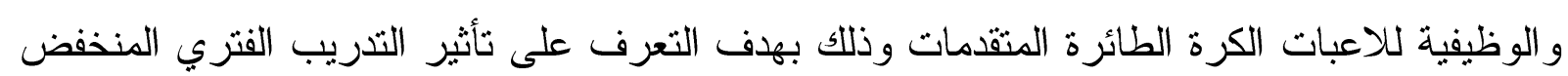
و المرتفع الثدة في تطوير القدرات البدنية و الوظيفية للاعبات الكرة واستخدم الباحث المنهج التجريبى

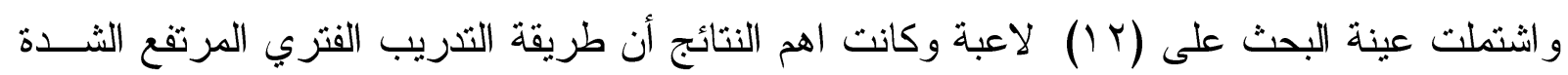
من الطرق التي تسهم بشكل فعال في تطوير المتغيرات الوظيفية و البدنية قبد الدراسة للمتقدمات بالكرة الطائرة .

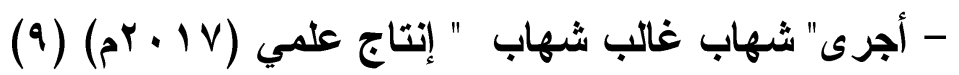

دراسة عنوانها تأثير منهج تدريبي بطريقة التدريب الفتري المرتفع الثدة لنطوير بعض القدرات البدنية و المهارية بالكرة الطائرة وذلك بهدف تأثثر منهج تدريبي بطريقة التدريب الفتري المرتفع الثدة لتطوير بعض القدرات البدنية والمهارية بالكرة الطائرة واستخدم الباحث المنهج التجريبى واشتملت عينة البحث على (1) (1) لاعب وكانت اهم النتائج أن طريقة التدريب الفتري المرتفع الثدة من الطرق التي تسهم بشكل فعال في تطوير القدرات البدنية و المهارية قيد البحث .

- أجرى" واضح احمد الامين " إنتاج علمي (17 + (17) (17) دراسة تأثبر التدريب الفتري مرتفع الثدة على تتمية بعض الصفات البدنية لعدائي ألعاب القوى مسافات نصف طويلة وذلك بهدف التعرف نأثير التدريب الفتري مرتفع الثدة على تتمية لهية بعض الصفات البدنية لعدائي ألعاب القوى مسافات نصف طويلة ، واستخدم الباحث المنهج التجريبى واشتملت عينة البحث على (9) لاعبين وكانت اهم النتائج وجود فروق دالة احصائية لصالح المجموعة التجريبية في الصفات البدنية لعدائي العاب القوي . 
در اسة عنو انها أثر التدريب الفتري مرتفع الثدة في تطوير بعض القدرات البدنية و المهارية للمدافع الحر في الكرة الطائرة وذلك بهدف التعرف علي أثر استخدام التدريب الفتري مرتفع الثدة في تطوير بعض القدرات البدنية والمهارية للمدافع الحر في الكرة الطائرة، واستخدم الباحث

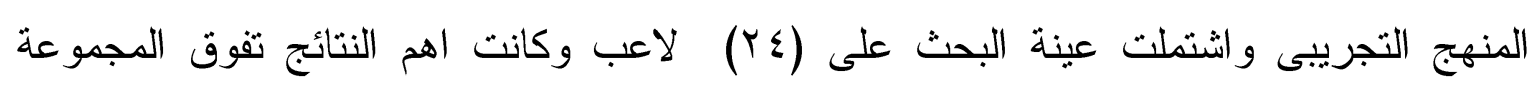

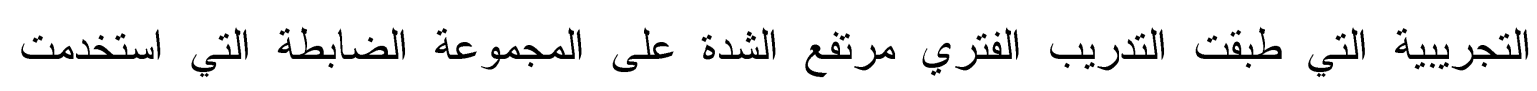

$$
\text { التدريب الاعتبادي. }
$$

- أجزى" امين خزعل عبده " (11) - (1) (0)

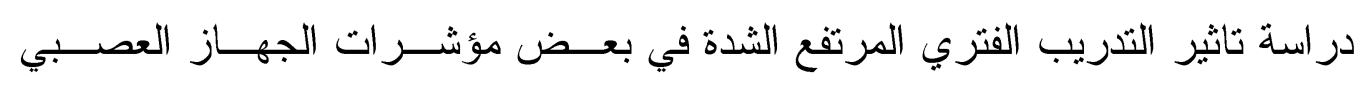

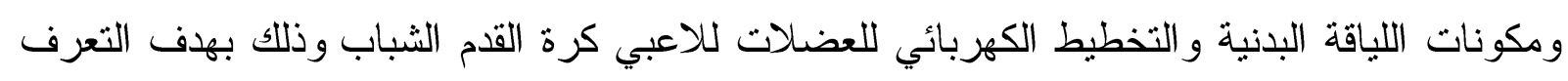
علي ثاثير التدريب الفتري المرتفع الثندة في بعض مؤشر ات الجهاز العصبي ومكونات اللياقة البدنيـــة

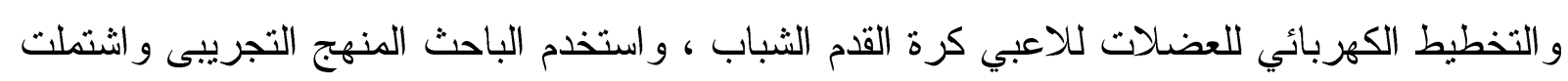
عينة البحث على (r ا) لاعب ودلت النتائج إلي معنوية الفروق بين الاختبارين القبلي و البعدي ولصالح

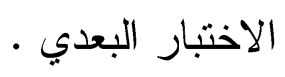

ثانيا: الارسات المرجعيه الاجنبيه: زيميك واخرون (IV) (zimek et al) (2)

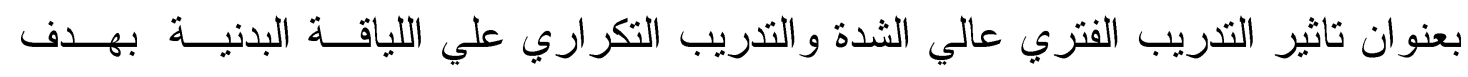

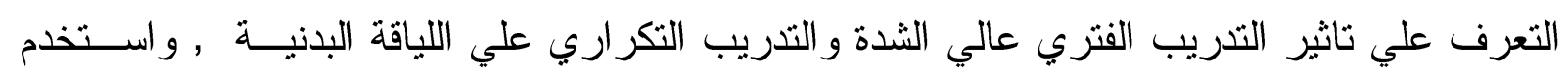

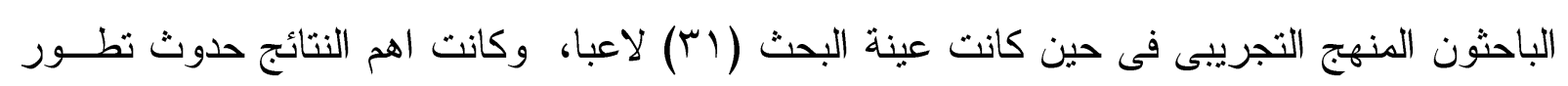

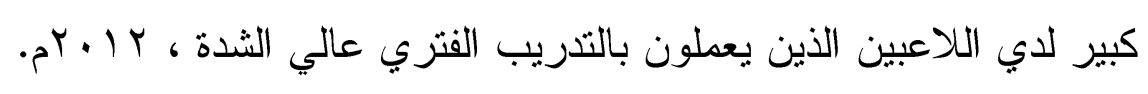
اوجه الاستفاده من الدراسات السابقه: استفاد الباحث من خلال اطلاعه على الدراسات السابقة مايلى ل الم ا ـ من حيث التوصيات تم الاحتيارلعدد منها جدير بالبحث حيث تبدا من حيث انتهى الاخرين . 
r. استفادت الدراسة الحالية من الدراسات المرجعية فى كيفية اختيار الدنهج الملائم لطبيعة اجر اء وظروف الدراسة.

r. اختيار وسائل جمع البيانات الخاصة بالدراسات المرجعية والمرتبطة حيث واجهت الباحث لكيفية احتيار الوسيلة الملائمة لطبيعة البحث.

ع. المعالجات الاحصائية فى الدراسات السابقة وجهت الباحث الى المعالجات التى تتناسب وطبيعة الدراسة.

ه. ساهمت البحوث و الدر اسات المرجعية فى تفهم الباحث حدود مشكلة البحث.

T. ساعدث الباحث فى التعرف على طريقة عرض النتائج وتفسيرها.

V. اظهرت للباحث مدى الحاجة الى اجر اء المزيد من تلك الدراسات الخاصة بالصم

اجراءات البحث.

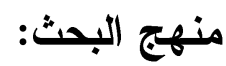

استخدم الباحث المنهج التجريبي لمناسبته لطبيعة هذا البحث، من خلال التصميم التجريبي للمجموعة التجريبية الواحدة والذي يعتمد على القياس القبلي والبعدي للاختبارات البدنية والاداءات الحركية المركبة قيد البحث.

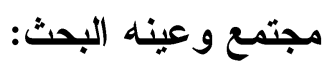

يمثل مجتمع البحث لاعبين أندية الريشة الطائرة تحت سن 19 سنة بجمهورية مصر العربية وعددهم (ع () نادي و عدد اللاعبين المسجلين بسجلات الإتحاد المصري للريشة الطائرة للعام

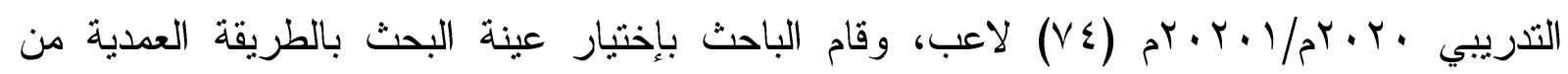
لاعبين الريشة الطائرة من نادي طلائع الجيش الرياضي وعددهم (• () لاعبين بالإضافة إلى عينة الدراسات الإستطلاعية من نادي الثمس الرياضي و عددهم (^) لاعبين، ليصبح إجمالي العينة الكلية ( n)

وقد قام الباحث بإجر اء التجانس لعينة البحث في متغيرات النمو التالية السن - الطول - الوزن

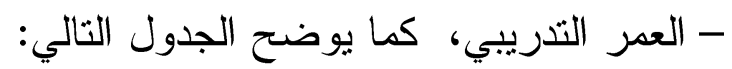




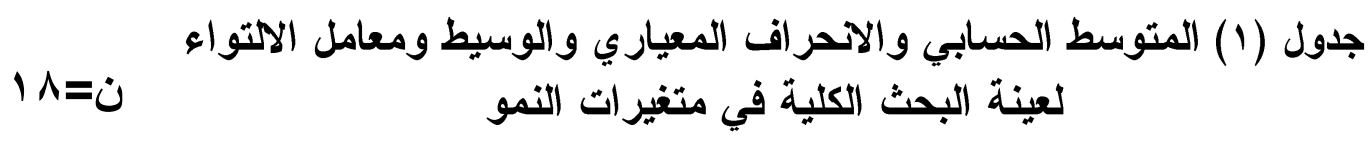

\begin{tabular}{|c|c|c|c|c|c|c|}
\hline الاتو اء & الالمعراف & الوسيط & الحسابى & وحدة & المتغيــــــــــــــرات & p \\
\hline$. .99-$ & $r . r)$ & vo & Vr. $9 \varepsilon$ & كيلوجرام & الــــــــوزن & 1 \\
\hline.$+r 1$ & \&.r & $1 \vee 9.0$. & $1 \vee q .9 \varepsilon$ & سنتيمتر & الطــــــــول & r \\
\hline 1.11 &..$v$. & IV & IV.\& & سنة & العــــــن & $r$ \\
\hline$. .1 \cdot-$ & I.Vr & 1.0. & $\Lambda . \leqslant \varepsilon$ & سنة & العمر التدريبى & $\varepsilon$ \\
\hline
\end{tabular}

أدوات ووسائل جمع البيانات: - استمار ات تسجيل البيانات.

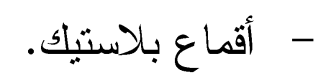
- كر ات ريشة طائرة. - - مضارب ريشة طائرة.

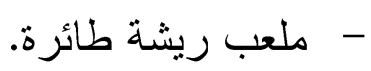
medical scale for weiglit(kg)ميزان طبي معاير لقياس الوزن (كجمة - شريط قياس بالسم. - ساعات إيقاف (· (1/ بنانية).

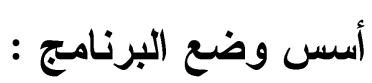

انطلاقا من أهداف البحث وخصائص عينة البحث و الاستفادة بآر اء الخبر اء تم وضع الأسس التالية للبرنامج التدريبي المقترح للارتقاء بمستوى القدرات الحركية لعينة البحث وبما يتناسب مع أهداف البحث : قام الباحث بتحديد الجوانب الرئيسية في إعداد البرنامج التدريبي المقترح من خلال المسح المرجعي لحصر التدريبات الخاصة بالقدرات الحركية والتي تشكل محتوى البرنامج التدريبي المقترح. تم ترنيب الوحدات التدريبية من السهل إلى الصعب ( الحجم - الثدة - الكثافة) لملائمنها للمرحلة السنية و المستوى المهارى للاعبين عينة البحث. تم تحديد مدة تتفيذ البرنامج التدريبي المقتر ح وهى ( • (1 ) أسابيع •

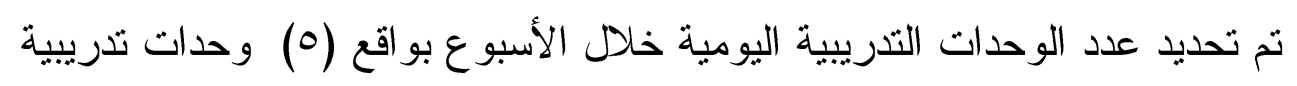


تم تحديد زمن الوحدات التريبية حيث بلغ متوسط زمنها مابين 0؛: |Y| ق بدون

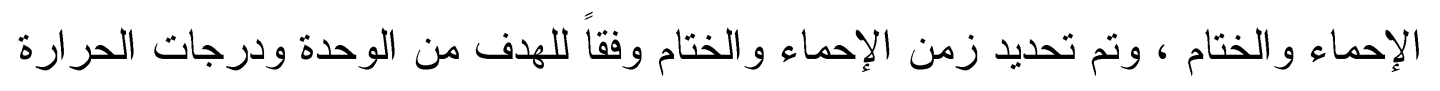

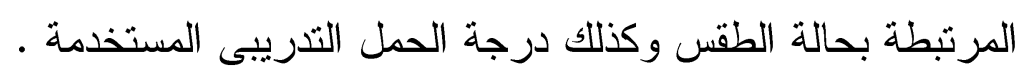
تم تحديد دورة الحمل الأسبوعية بتشكيل (Y:Y) بمعنى يوم راحة او حمل متوسط يعقبة يومين حمل اكثر ارتفاعاً ( عالى فأقصى ) تم تحديد دورة الحمل الفترية بتشكيل (1:Y) بمعنى أسبوع حمل متوسط يليه اسبو عين حمل مرتفع تم تجميع تمرينات الوحدة التدريبية خلا الأسبوع ، مع مراعاة اختيار واختلاف التمرينات وزمنها من وحدة تدريبية إلي وحدة تدريبية أخرى خلال الأسبوع وذللك لتسهيل وتثبيت أداء التمرينات علي عينة البحث من الناشئين.

(القياسات القبلية:

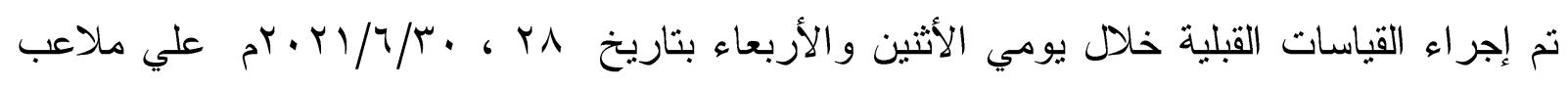

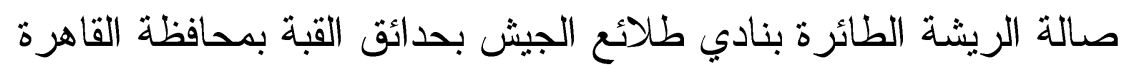

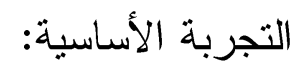

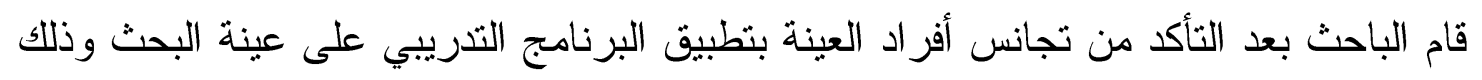

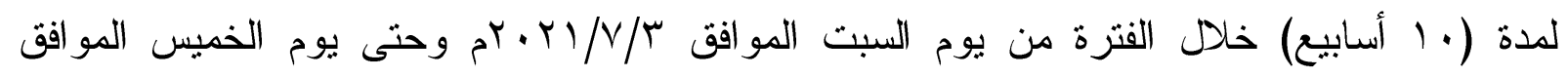
. $r \cdot r 1 / 9 / 9$

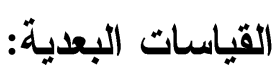

تم إجراء القياس البعدي للمجموعة التجريبية قيد البحث بنفس الثروط و التعليمات و الظروف

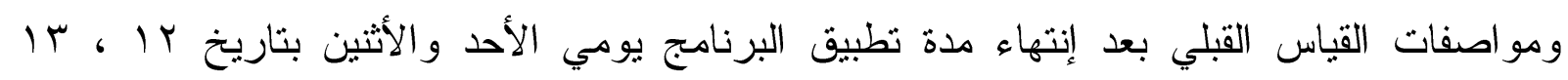

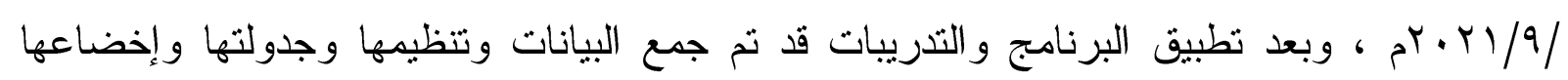
للمعالجة الإحصائية.

المعالجات الإحصائية المستخدمة: تم استخدام المعالجات الإحصائية التالية:

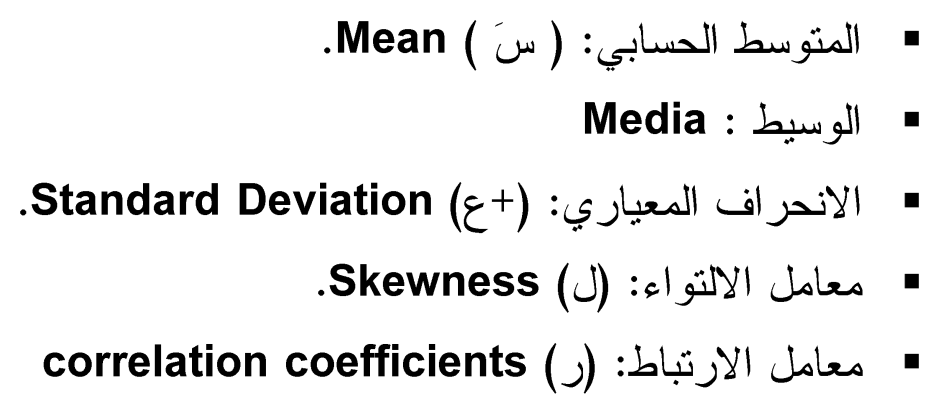




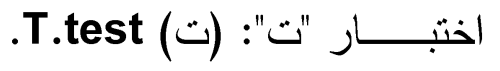

Improvement Ratio : نسب التحسن

مستخدماً في هذه المعالجات البرنامج الإحصائي :SPSS.

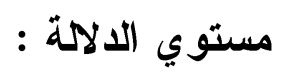

اتخذ الباحث مستوى دلالة (معنوية) عند (0., • ).

عرض ومناقشة النتائج

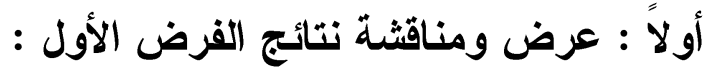

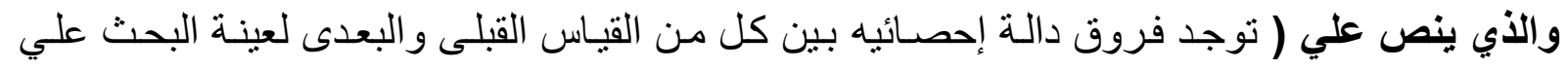

بعض المتغيرات البدنية للاعبي الريشة الطائرة).

جدول (r)

دلالة الفروق بين متوسط نتائج القياسين القبلي والبعدي للمجموعة إلباني

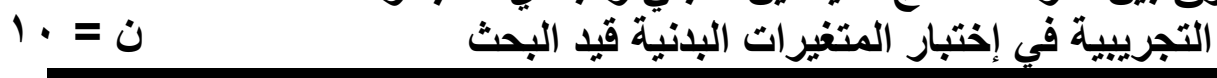

\begin{tabular}{|c|c|c|c|c|c|c|c|c|}
\hline \multirow{2}{*}{$\begin{array}{c}\text { التحسبة } \\
\text { \% }\end{array}$} & \multirow{2}{*}{ قالمسمة } & \multicolumn{2}{|c|}{ القياس البعدي } & \multicolumn{2}{|c|}{ القياس القبلي } & \multirow{2}{*}{ القياس } & \multirow{2}{*}{ القياسات } & \multirow[b]{2}{*}{ r } \\
\hline & & المعياري & الحستبي & المعياري & الحستوبي & & & \\
\hline 51.77 & $1 . .7$ & $1 . \leqslant V$ & $1 \cdot . r \cdot$ & $1 . \varepsilon$ & V.Y. & سنتيمتر & المرونة & 1 \\
\hline Y7.05 & $V . Y q$ &.$\mu$ & 1.00 & $\because r V$ & r.11 & ثانية & السرعة & $r$ \\
\hline$r \cdot$ & $1 \cdot . r$. & T.MT & 18.7. & r.یr & Yr & ثانية & الرشاقة & $r$ \\
\hline M. Vo & $\vee . \vee O$ &.$\wedge r$ & $\varepsilon . \mu$. & .90 & $7 . r$. & ثانية & 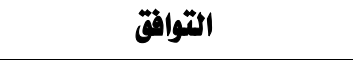 & $\varepsilon$ \\
\hline $7 V . M I$ & Y) & .90 & A.V. & $.9 r$ & $0 . r$. & متر & القوة الميزة بالسرعة للقدمين & 0 \\
\hline $77.7 \mathrm{~V}$ & $r \leqslant . \leqslant r$ & 1.1 & $1 T .0$. & .99 & $\wedge .1$ & عدد & القوة المييزة بالسرعة للدراعين & 7 \\
\hline
\end{tabular}

قيمة "ت" الجدولية عند مستوى ه ... ودرجات حرية 9 = Y Y Y r.

تظهر نتائج جدول (r) وجود فروق ذات دلالة إحصائياً في متغيرات المرونة والسرعة

و الرشاقة والتوافق والقوة المميزة بالسرعة للقدمين والذراعين بين القياس القبلي و القياس البعدي

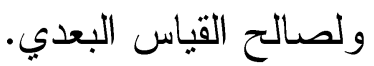

ويرجع الباحث أن هذه الفروق تزجع إلى فاعلية البرنامج التدريبي المقترح و الذي تكون من

عدد ·1 أسابيع تدريبية بإجمالي .0 وحدة وكانت الأسابيع التدريبية المؤثرة بمجموع (؟) أسابيع بالحمل المؤثر حيث أن الأسابيع المؤثره هي التى تحدث التغيير للاعبين ويتم فيها تطوير المستوي

البدني للعينة قيد الدراسة، وإحتوى البرنامج على مجموعة من التدريبات المكثفة لتطوير المتغيرات البدنية بإستخدام أدوات مساعدة مثل الأساتكا المطاطة والكور السويسرية و الصناديق و الأدوات المعلقة 
مثل trx والأقماع، حيث راعى الباحث في تصميم البرنامج التدريبي عملية تقنين الحمل بمكوناته الثلاثة (الثدة - الحجم - الكثافة)، وكذلك انتظام أفراد الهجموعة التجريبية وبذل الجهر أثناء التدريب، الأمر الذي ساهم بدرجة كبيرة في تحسين مستوى تلك المتغيرات البدنية لدى عينة البحث، حيث كانت الفروق بين القياس القبلي و البعدى لصالح القياس البعدي في جميع المتغيرات البدنية قيد البحث. أظهرت نتائج جدول (Y) وجود فروق دالة إحصائية بين متوسطي القياسين القبلي والبعدى

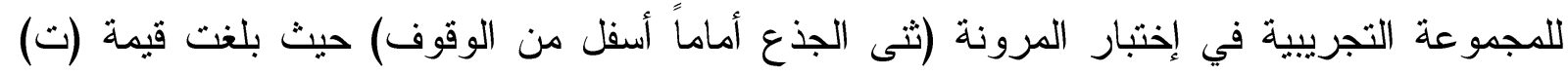

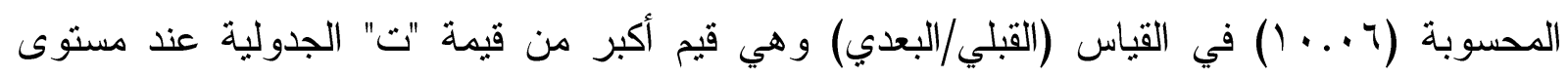

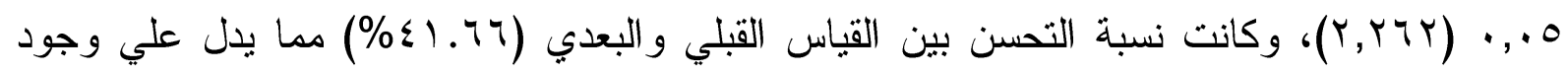

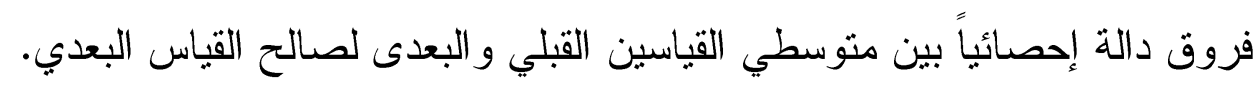
ويعزي الباحث هذه الفروق المعنوية لإختبار المرونة بين متوسطي القياسين القبلي والبعدي لئي إلي تدريبات المرونه التى تم إستخدامها داخل الوحدات التدريبية وربط الصفة البدنية بنوعية الأداء

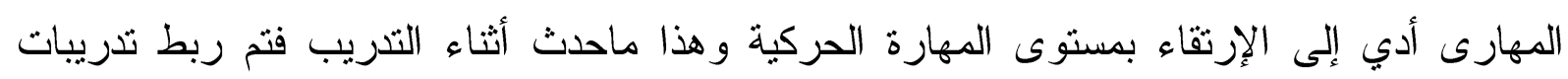

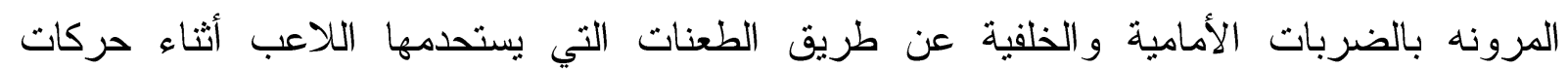

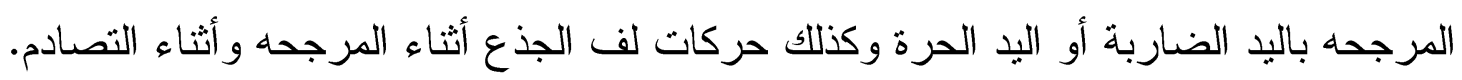

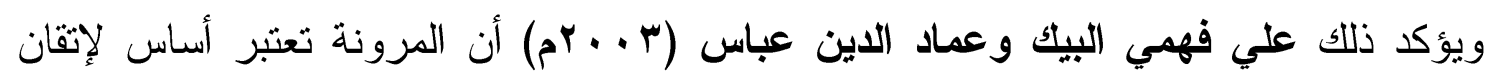

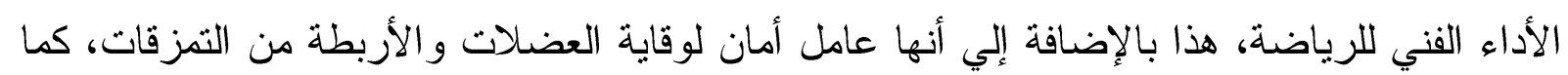

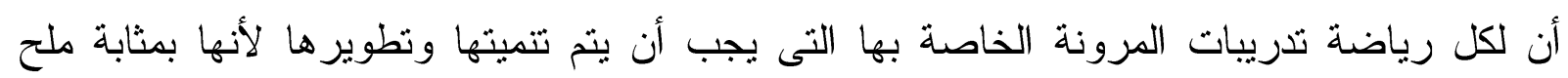

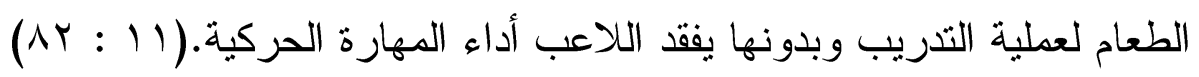
أظهرت نتائج جدول ( r ) وجود فروق دالة إحصائية في إختبار القوة المميزة بالسرعة للرجلين والذراعين بين متوسطي القياسين القبلي و البعدى للهجموعة التجريبية في إختبار القوة المميزة

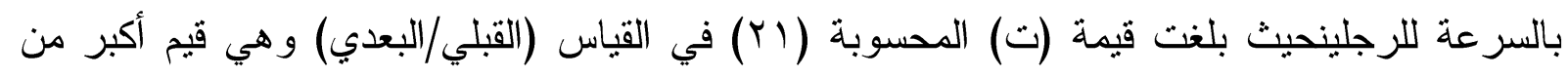

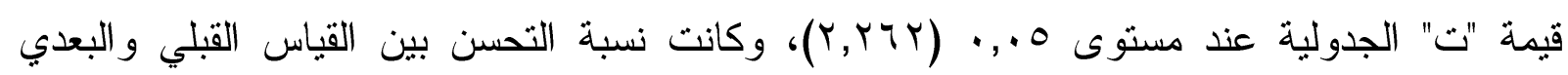

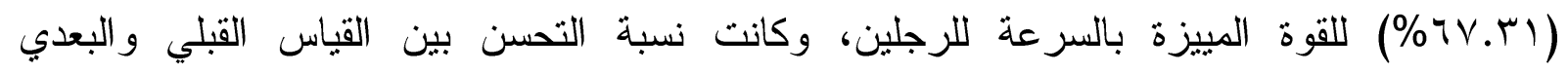

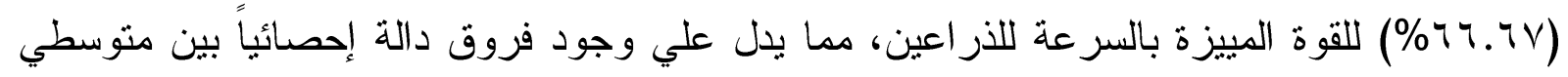
القياسين القبلي و البعدى لصالح القياس البعدي. ويعزي الباحث هذه الفروق المعنوية بين متوسطي القياسين القبلي و البعدي إلي التنديب المققن

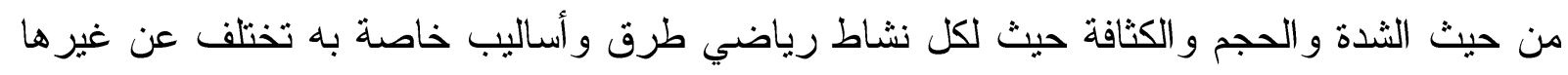
من الألعاب وراعي الباحث أن تكون تدريبات القوة المميزة بالسرعة للرجلين داخل رئل الوحدات التدريبية 
لما تحتوية لعبة الريشة الطائرة من التحرك المفاجئ إلي جميع أركان الملعب و النزول السريع لضرب الكرة وكذلك القيام السريع بعد الضرب و العودة إلي منطقة التمركز . لإنا

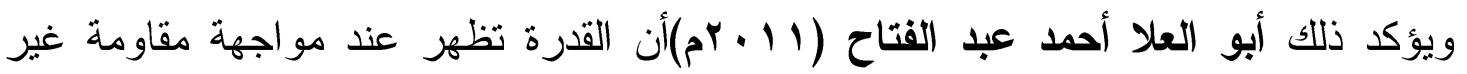

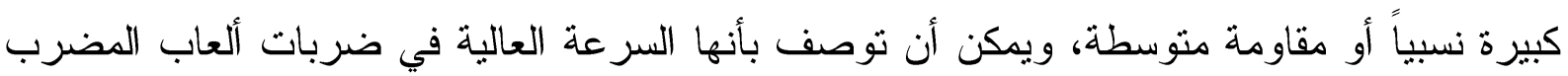

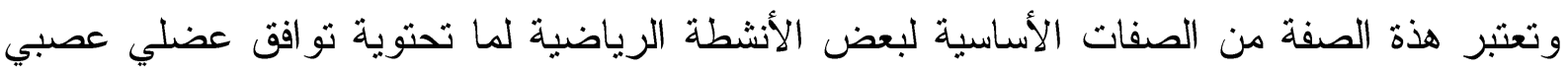
ويجب التدريب عليها داخل الوحدات التدريبيه وبطرق تقنين علمية ومنظمه.(1: (Y I)

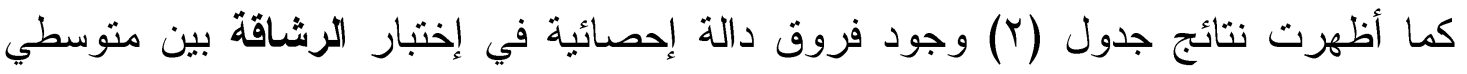

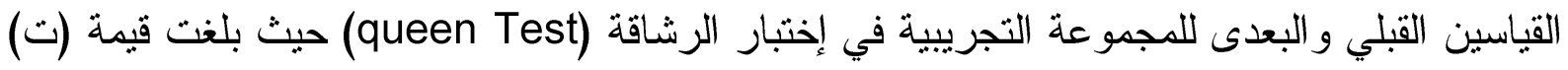

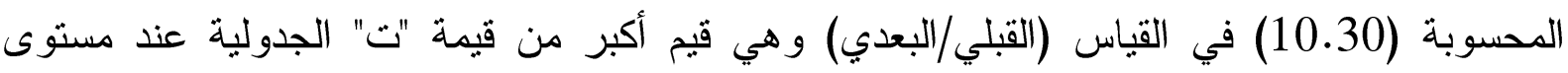

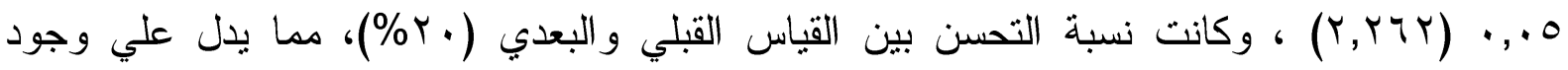
فروق دالة إحصائياً بين متوسطي القياسين القبلي و البعدى لصالح القياس البعدي. ويعزي الباحث هذه الفروق المعنوية بين متوسطي القياسين القبلي و البعدي إلي تدريبات

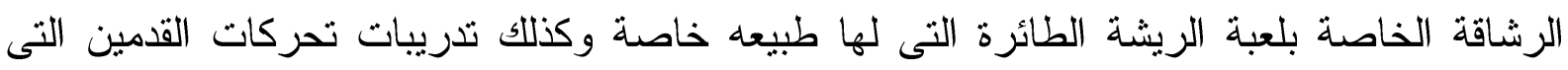

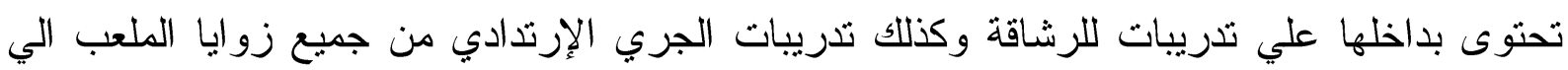

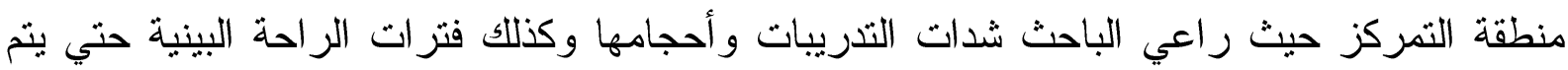
تنمية وتطوير الرشاقة بالصورة العلمية.

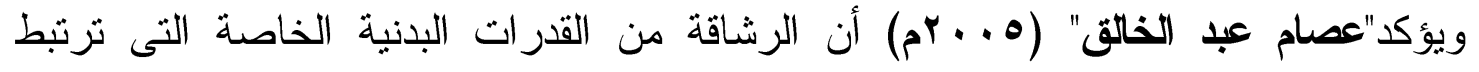

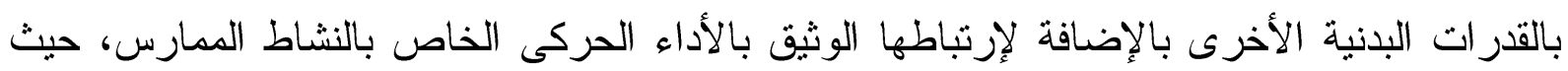

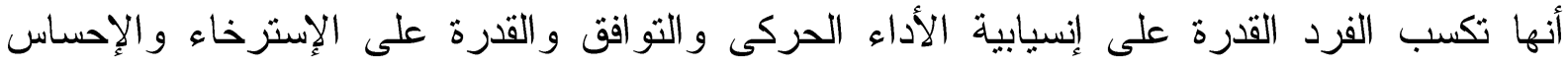

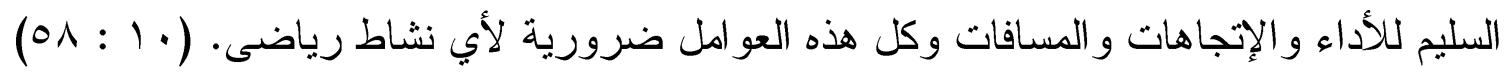

كما أظهرت نتائج جدول (Y) وجود فروق دالة إحصائية في إختبار التوافق بين منوسطي

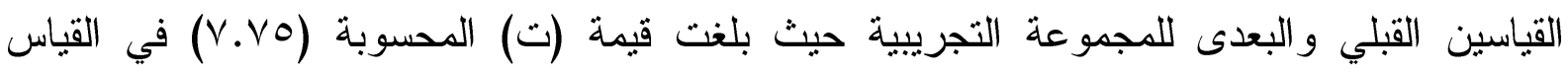

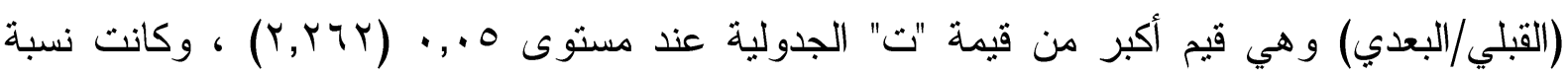

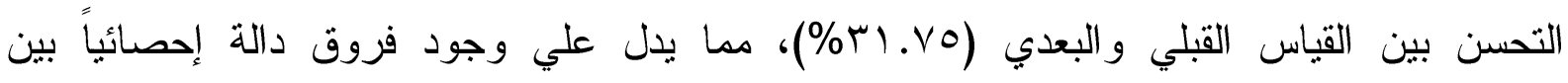
منوسطي القياسين القبلي و البعدى لصالح القياس البعدي.

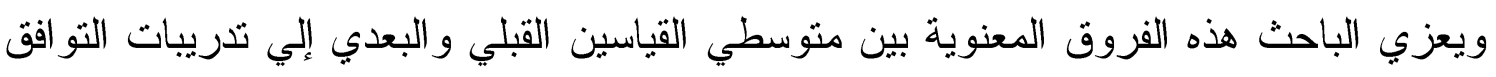

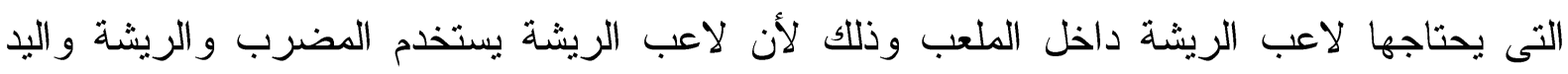

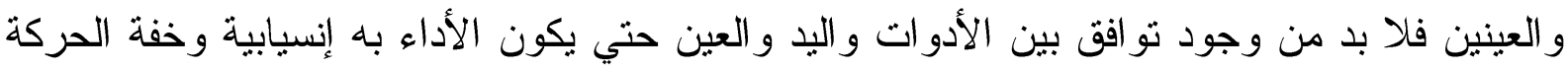

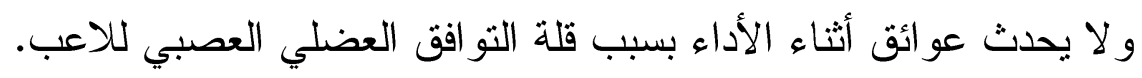


ويتفق هذا مع ماأشار إلبة علي البيك وآخرون (9 . . بم) إلي ضرورة تتمية التوافق حتي لايتم إستتفاذ

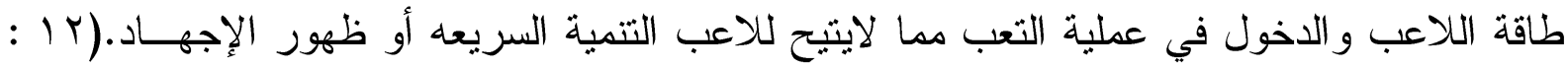

أظهرت نتائج جدول(Y) وجود فروق دالة إحصائية بين متوسطي القياسين القبلي و البعدى

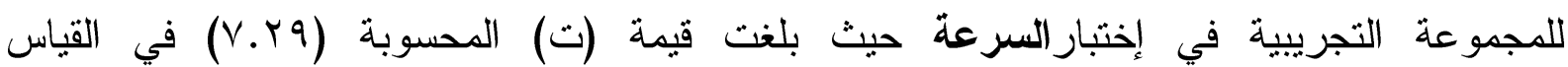

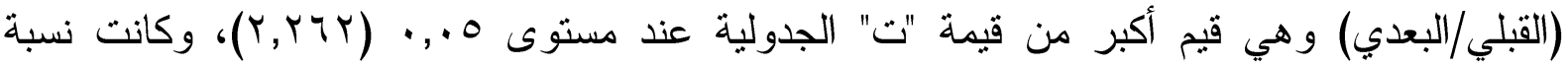

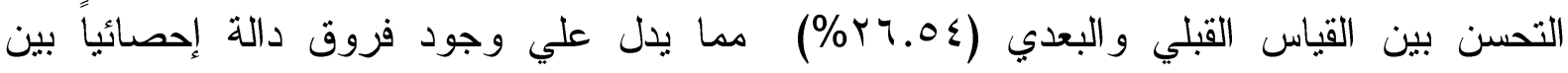
متوسطي القياسين القبلي و البعدى لصالح القياس البعدي.

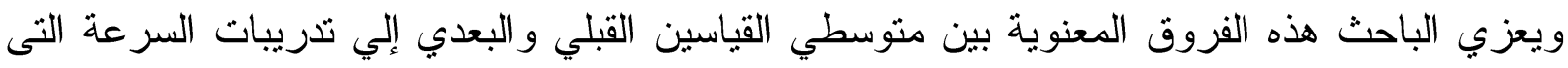

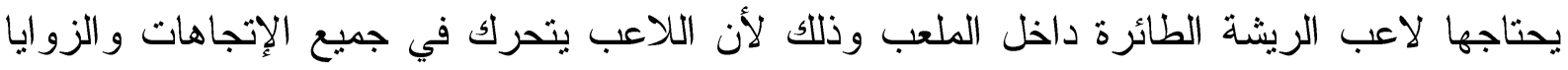

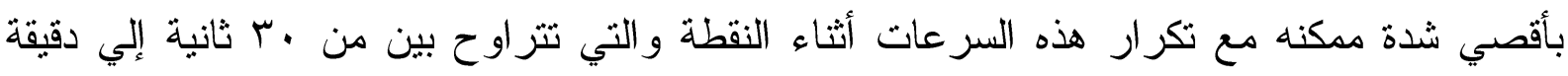

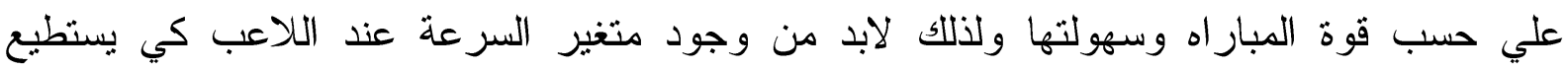

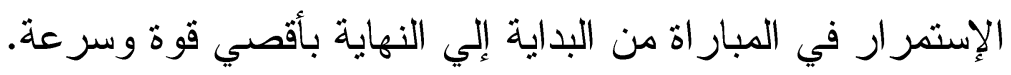

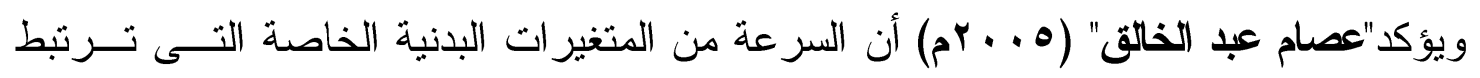

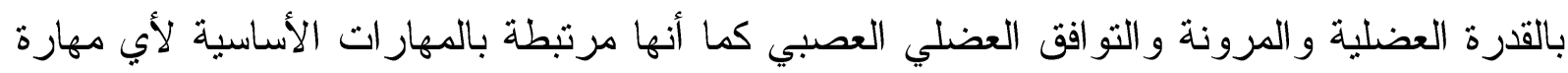

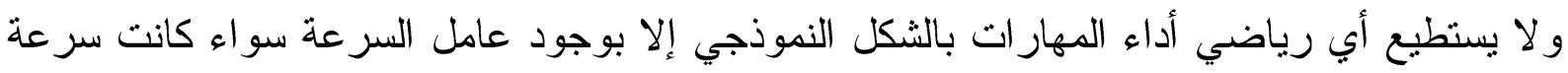

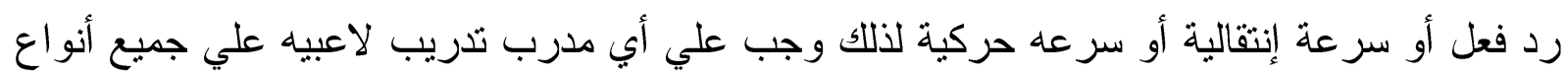

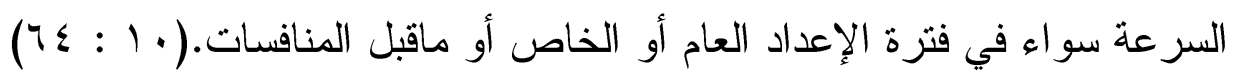
وتشير هذه النتائج إلى أن البرنامج التدريبي باستخدام التدريبات الفترية مرتفعة الثدة قد أدى الي تتمية وتطوير المرونة و السرعة و الرشاقة والتوافق و القوة المميزة بالسرعة للقدمين و الذراعين، وذللك حيث أن إستخدام برامج تدريبية ذات تخطيط جيد و عناية منظمة، تؤدى إلى تتمية المتغيرات البدنية المختلفة، وأن البرامج المقننة والتي تراعى عند تصميمها الأسس والمبادئ العلمية المنظمة و التزكيز على التمرينات الخاصة و التي تعمل في نفس المسار الحركي للمهارات المختلفة تؤدى إلى لقى تتمية وتحسين المتغيرات البدنية ، حيث أن هذه التدريبات الفترية مرتفعة الثدة تعمل علي تطوير المتغيرات البدنية عند أداء المهارات بصورة مباشرة حيث تكون أكثر تركيزاً على تتمية الأداء المهارى و البدني معاً في نفس الوقت.

وبهذا يتحقق فرض البحث الأول و الذى ينص على أنه " توجد فروق دالة إحصائيا بين كل من القياس القبلى والبعدى لعينة البحث علي بعض المتنغير ات البدنية للاعبي الريشة الطائرة. 
علي ضوء نتائج هذا البحث وفي حدود خطة وإجر اءات البحث يمكن استخلاص ما يلي:

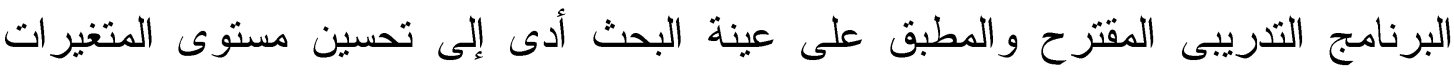

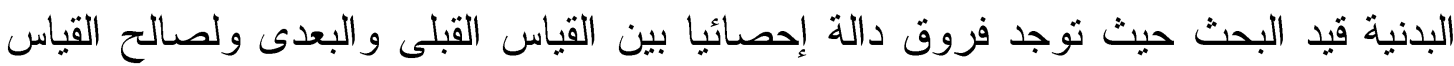

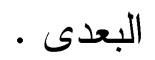
تتمية المتغيرات البدنية من خلال التدريب الفتري مرتفع الثدة يؤدى الى الإرتقاء بالمستوى

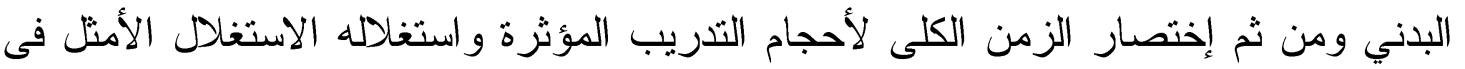

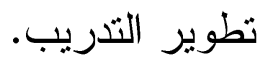
التدرج بالأحمال التدريبية في أول ثلاث أسابيع حتى لايؤدي إلي التعب المبكر و الإجهاد.

فى ضوء ما أظهرته نتائج البحث و الإستخلاصات التى نم التوصل اليها يوصى الباحث بالأتى

تطبيق البرنامج التدريبى المقترح لتطوير المتغيرات البدنية على لاعبي الريشة الطائرة. ضرورة اهتمام الدربين بطريقة التدريب الفتري مرتفع الثندة ووضعها فى تدريبات متدرجة الصعوبة من حيث التركيب بما يجعاهيا أكثر تشويقاً وتشابهاً لما يحدث في المباريات.

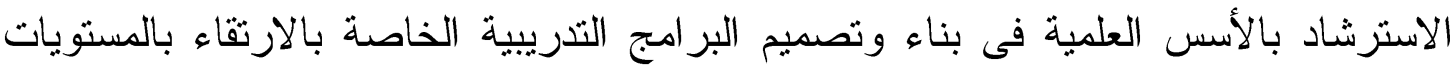
البدنية و المهارية والخططية للاعبي الريشة الطائرة.

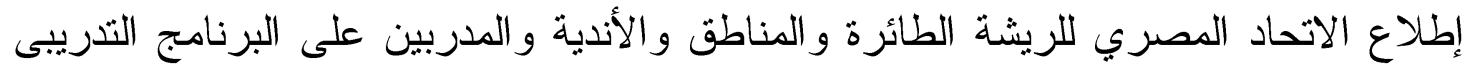

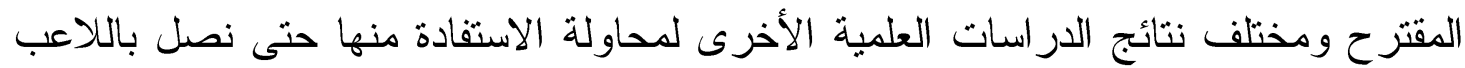

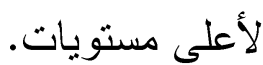

إتباع اسلوب التدريب الفتري مرتفع الثندة عند تتمية المتغيرات البدنية الخاصة بلاعبى الريشة الطائرة الاستفادة من نتائج الدر اسة وفتح مجالات بحث جديدة فى نفس الاتجاه و المجال لتصميم برامج تدريبية غير تقليدية وعلاقتها بجو انب أخرى.

\section{المراجيع}

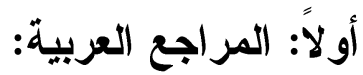
1- أبو العلا أحمد عبد الفتاح : التدريب الرياضى المعاصر، دار الفكر العربي، القاهرة ، 11 أمبح.

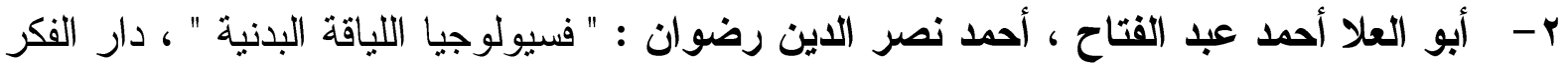

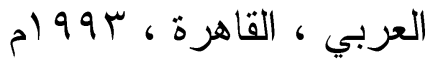


r- احمد جمال عبدالمنعم : " دراسة تأثثر التدريب الفتري مرتفع الثندة على القدرات البدنية الخاصة

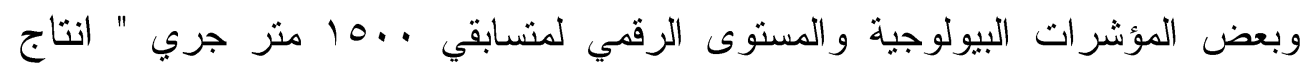

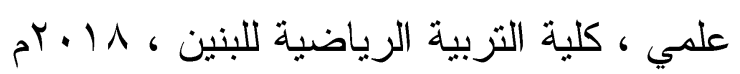

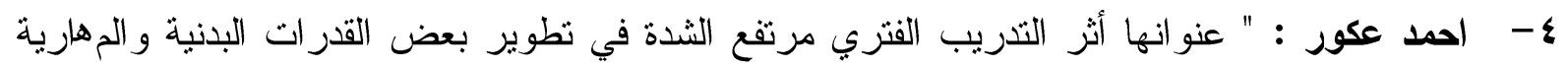

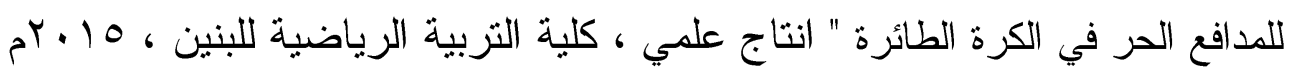

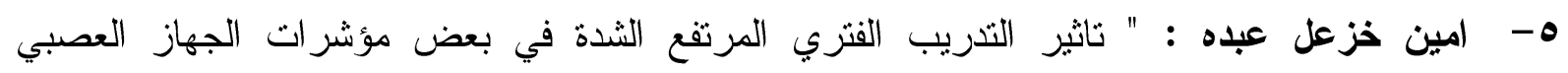

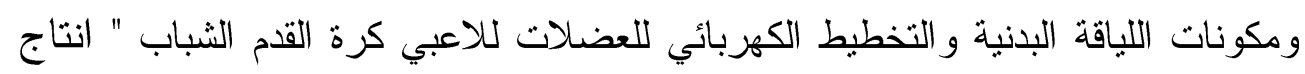

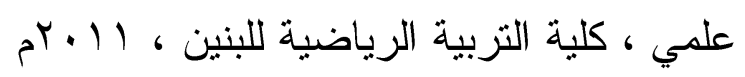

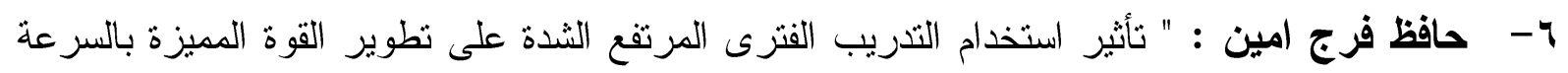

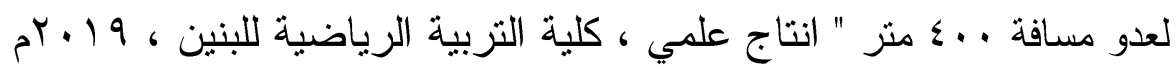

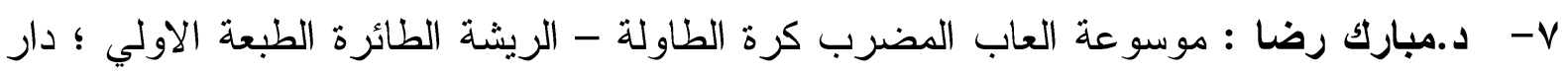

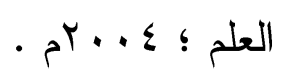

1- د.وسام صلاح عبد الحسين : الريشة الطائرة بين الممارسة والمنافسة ؛ الطبعة الاولي ؛

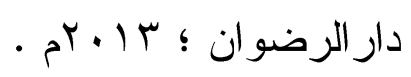

9- شهاب غالب شهاب : " تأثثر منهج تدريبي بطريقة التنريب الفتري المرتفع الثدة لنطوير بعض

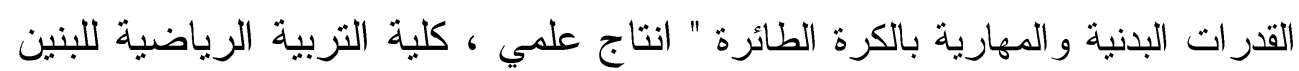

$$
\mathrm{r}^{\mathrm{r} \cdot 1 \mathrm{~V}} 6
$$

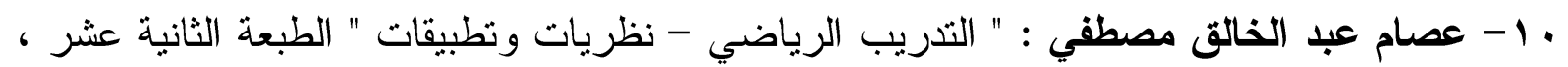

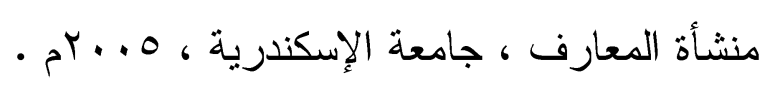

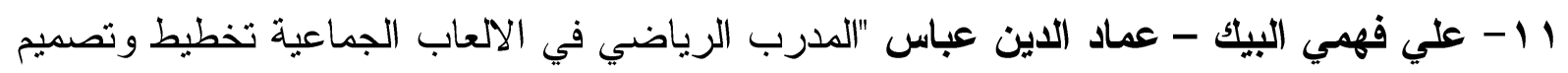

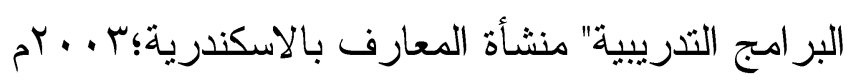

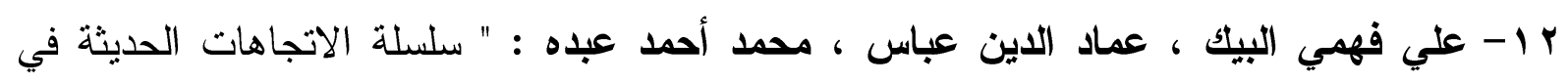

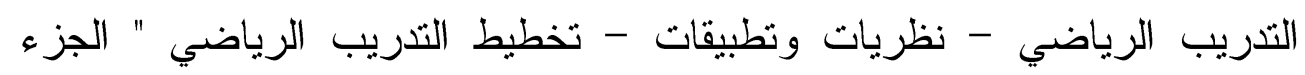

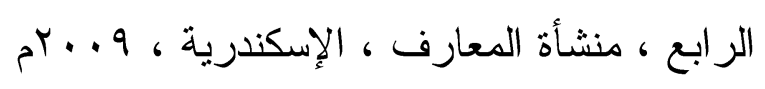

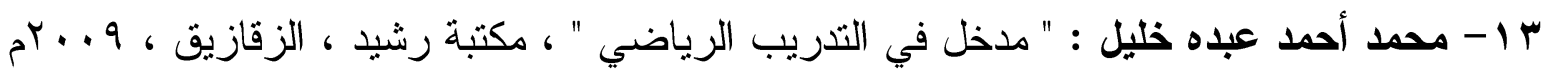

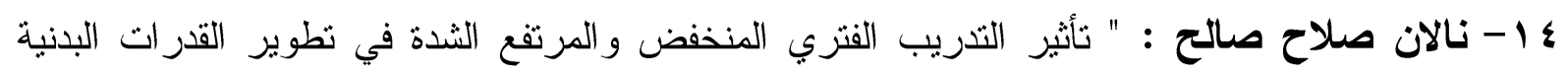
و الوظيفية للاعبات الكرة الطائرة المتقدمات " انتاج علمي ، كلية التربية الرياضية

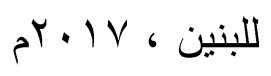

ه 1 - هلال حسن الجيزاوي: التفكير الخططي في الريشة الطائرة ؛الطبعة الاولي ؛ دار الوفاء ؛

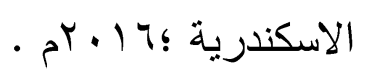


1 ا - واضح احمد الامين : " تأثير التنريب الفتري مرتفع الثدة على تنمية بعض الصفات البدنية لعدائي

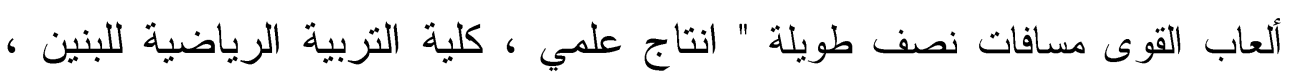

$$
\text { r. } 11 \text { r }
$$

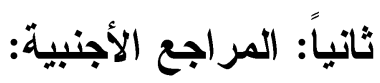

17- zimek: The effect of high intensity interval training and repetitive training on physical fitness ، 2012.

18- Tony, grice : Badminton steps to success $₹ .$. l. 